\title{
GAMBARAN PENGGUNAAN OBAT ANTIHIPERTENSI PADA PASIEN PREEKLAMPSIA DI INSTALASI RAWAT INAP RUMAH SAKIT BHAYANGKARA KOTA PALANGKA RAYA TAHUN 2016
}

\author{
Syahrida Dian Ardhany ${ }^{1}$ \\ ${ }^{1}$ Program Studi DIII Farmasi, Fakultas IImu Kesehatan, Universitas Muhammadiyah \\ Palangka Raya, Palangka Raya, Kalimantan Tengah \\ e-mail : chass501@gmail.com
}

\begin{abstract}
ABSTRAK
Preeklampsia dan eklampsia menempati urutan kedua penyebab kematian ibu sedangkan yang pertama adalah pendarahan. Oleh karena itu diagnosis dini preeklampsia yang merupakan tingkat pendahuluan eklampsia, serta penanganannya perlu segera dilaksanakan untuk menurunkan angka kematian ibu dan anak. Penelitian ini bertujuan mengetahui gambaran penggunaan antihipertensi pada pasien preeklampsia dan untuk mengetahui ketepatan antihipertensi preeklampsia di Instalasi rawat inap Rumah Sakit Bhayangkara Kota Palangka Raya ditinjau dari aspek tepat indikasi, tepat obat, tepat pasien dan tepat dosis dengan standar acuan JNC 7. Jenis penelitian ini adalah penelitian non-eksperimental. Penelitian dilakukan secara observasi yang datanya diambil secara retrospektif dan dianalisis secara deskriptif non analitik. Hasil penelitian menunjukkan jenis obat yang digunakan adalah metildopa sebanyak $80 \%$, nifedipin $60 \%$ dan $\mathrm{MgSO}_{4} 60 \%$ dan pada evaluasi penggunaan obat di instalasi rawat inap Rumah Sakit Bhayangkara Kota Palangka Raya tahun 2016 tidak ditemui adanya ketidaktepatan indikasi, obat, dosis dan pasien.
\end{abstract}

Kata Kunci : Antihipertensi,Palangka Raya, Preeklamsia

\begin{abstract}
Preeclampsia and eclampsia is second rank cause of maternal mortality, the first is bleeding. Therefore, the initial diagnosis of preeclampsia, which is the beginning of eclampsia, and its treatment needs to be immediately implemented to reduce maternal and child mortality. This study aims to know the description of antihypertensive preeclampsia in Bhayangkara Hospitals of Palangka Raya to review of aspect of the right indication, the right drug, right patient, and the right dose of the reference JNC 7. This type of research is non experimental research. The research was done by observation which the data was taken retrospectively and analyzed by descriptive non analitic. The result showed that the type of drug used was $80 \%$ of methyldopa, $60 \%$ nifedipine, $\mathrm{MgSO}_{4} 60 \%$ and of evaluation of drug use in Bhayangkara Hospitals of Palangka Raya in 2016 did not find indication, drug, dose and patient that not right.
\end{abstract}

Keywords: Antihypertensive, Palangka Raya, Preeclampsia 


\section{PENDAHULUAN}

Angka Kematian lbu (AKI) merupakan salah satu indikator keberhasilan pembangunan pada sektor kesehatan. AKI mengacu pada jumlah kematian ibu mulai dari masa kehamilan, persalinan dan nifas ${ }^{1}$. Terdapat dua kategori kematian ibu yaitu disebabkan oleh penyebab langsung obstetri yaitu kematian yang diakibatkan langsung oleh kehamilan dan persalinannya, dan kematian yang disebabkan oleh penyebab tidak langsung yaitu kematian yang terjadi pada ibu hamil yang disebabkan oleh penyakit dan bukan oleh kehamilan atau persalinan nya ${ }^{2}$.

Preeklampsia/eklampsia merupakan penyebab utama morbiditas dan mortalitas ibu dan bayi di dunia khususnya negaranegara sedang berkembang. Pada negara sedang berkembang frekuensi dilaporkan berkisar antara 0,3 persen sampai 0,7 persen, sedang di negara-negara maju angka eklampsia lebih kecil, yaitu 0,05 persen sampai 0,1 persen. Di Indonesia preeklampsia berat dan eklampsia merupakan penyebab kematian ibu berkisar 1,5 persen sampai 25 persen, sedangkan kematian bayi antara 45 persen sampai 50 persen $^{3}$. Survei Demografi dan Kesehatan Indonesia (SDKI) tahun 2012 menunjukkan peningkatan signifikan $\mathrm{AKI}$ di Indonesia sebesar $\pm 57 \%{ }^{4}$

Etiologi dan patofisiologi preeklampsia masih belum dapat dipahami dengan jelas sehingga menjadi tantangan dalam pencegahan penyakit tersebut. Strategi untuk mengatasi preeklampsia dan komplikasinya difokuskan pada deteksi dini penyakit dan tatalaksana terapi yang tepat. Tatalaksana terapi preeklampsia bergantung pada ketersediaan pelayanan obstetri emergensi termasuk antihipertensi ${ }^{5}$. Pengontrolan tekanan darah ibu dengan antihipertensi penting untuk menurunkan insidensi perdarahan serebral dan mencegah terjadinya stroke maupun komplikasi serebrovaskular lain akibat preeklampsia ${ }^{6}$. Berdasarkan latar belakang di atas, gambaran penggunaan antihipertensi pada pasien preeklamsia perlu dilakukan.

\section{METODOLOGI}

Jenis penelitian ini adalah jenis penelitian non-eksperimental, karena tidak memberikan perlakuan apapun pada subyek penelitiannya. Penelitian dilakukan secara observasional yang datanya diambil secara retrospektif dan dianalisis secara deskriptif non analitik. Sumber data dalam penelitian ini adalah rekam medik pasien ibu hamil dengan diagnosa preeklampsia yang menjalani rawat inap di Instalasi Rawat Jalan Rumah Sakit Bhayangkara Kota Palangka Raya tahun 2016 yang memenuhi kriteria inklusi.

Kriteria Inklusi :
a. Pasien
dengan
diagnosisi
preeclampsia. 
b. Pasien preeklampsia yang menjalani rawat inap di Instalasi Rawat Jalan Rumah Sakit Bhayangkara Kota Palangka Raya tahun 2016.

c. Pasien mempunyai data rekam medik lengkap sekurang-kurangnya meliputi : nama pasien, umur pasien, usia kehamilan, tekanan darah pasien, data penggunaan obat dan diagnosis penyakit.

Data diperoleh dari bagian rekam medik dengan melihat catatan medik dan perawatan. Pada evaluasi penggunaan obat dilakukan dengan metode analisis deskriptif kemudian dibandingkan dengan standar untuk mendapatkan ketetapan penggunaan obat pada masing-masing kasus.

1. Hasil penelitian dinyatakan dengan persentase tepat indikasi, persentase tepat obat, persentase tepat dosis, persentase tepat pasien dan persentase 4T (tepat indikasi, tepat obat, tepat dosis dan tepat pasien).

2. Persentase tepat indikasi diperoleh dari :

$=\frac{\text { Jumlah Kasus yang tepat indikasi }}{\text { Jumlah total } \text { kasus }} \times 100 \%$

3. Persentase tepat obat diperoleh dari : $=\frac{\text { Jumlah Kasus yang tepat obat }}{\text { Jumlah total kasus }} \times 100 \%$

4. Persentase tepat dosis diperoleh dari $=\frac{\text { Jumlah Kasus yang tepat dosis }}{\text { Jumlah total kasus }} \times 100 \%$

5. Persentase tepat pasien diperoleh dari :

$=\frac{\text { Jumlah Kasus yang tepat pasien }}{\text { Jumlah total kasus }} \times 100 \%$
6. Persentase 4T diperoleh dari :

$=$

Jumlah Kasus yang tepat indikasi,obat,dosis dan pasien Jumlah total kasus

$x 100 \%$

Adapun standar yang digunakan adalah The Sevent Report of the Joint National Committee on Prevention, Detection, Evaluation, and Treatment of High Blood Pressure 45 ${ }^{\text {th }}$ (JNC 7) oleh National Institutes of Health National Heart, Lung, and Blood Institute.

\section{HASIL DAN PEMBAHASAN}

\section{A. Karakteristik Pasien}

\section{Usia Ibu Hamil}

Berdasarkan usia ibu hamil, digolongkan menjadi pasien yang berumur 17-25 tahun, 26-35 tahun dan 36-45 tahun $^{7}$. Usia ibu pada saat hamil sangat penting mempengaruhi terjadinya hipertensi pada kehamilan. Ibu hamil yang berumur lebih dari 35 tahun cenderung mengalami preeklamsia berat karena pada umur yang sudah berlebih sistem hormone dan organ tubuh tidak seperti dulu atau melemah. Oleh karena itu rentan terhadap berbagai penyakit yang menyertai. Dan biasanya ibu hamil dengan umur 20-35 tahun juga sudah dapat mengalami preeklamsia ringan. Hal ini bisa dikarenakan kurangnya ibu untuk melakukan pemeriksaan antenatal ${ }^{8}$.

Menurut Gambar 1 dapat dilihat bahwa pasien ibu hamil dengan jumlah terbanyak yang didiagnosa menderita preeclampsia adalah pasien berusia 26-35 tahun, yaitu sebanyak 3 kasus (60\%). 
Sedangkan untuk pasien ibu hamil berusia 17-25 tahun tidak ditemukan kasus dan untuk pasien ibu hamil berusia 36-45 tahun sebanyak 2 kasus (40\%).

Berdasarkan hasil tersebut terdapat ketidaksesuaian antara hasil yang didapat dari teori diatas karena preeklampsia justru paling banyak terjadi pada usia ibu hamil antara 26-35 tahun sebanyak 3 pasien $(60 \%)$.

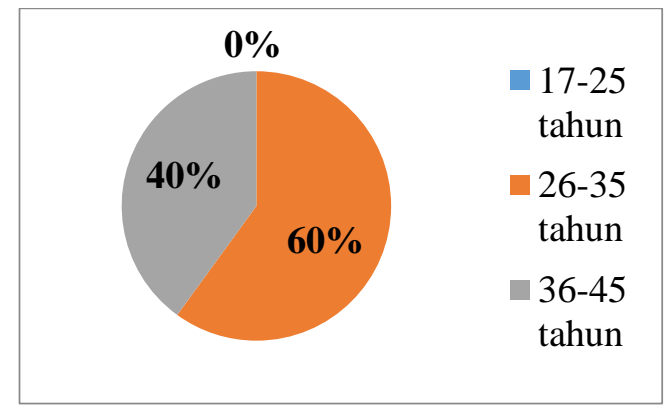

Gambar 1. Distribusi usia pasien preeklampsia di Rumah Sakit Bhayangkara Palangka Raya tahun $2016(\mathrm{~N}=5)$

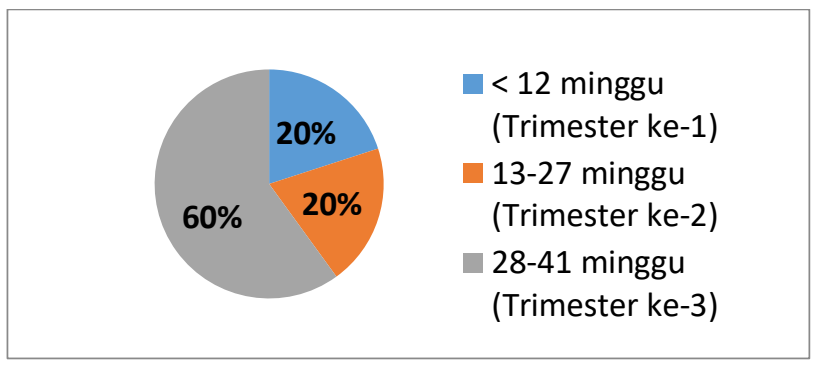

Gambar 2. Usia kehamilan penderita preeklampsia di Rumah Sakit Bhayangkara Palangka Raya tahun 2016

\section{Diagnosis}

Dari hasil data yang didapatkan dikelompokan menjadi 2 yaitu, tekanan darah ringan-sedang (tekanan darah sistolik 140-159 mmHg dan tekanan darah diastolik 90-99 $\mathrm{mmHg}$ ) dan kelompok berat (tekanan darah sistolik $\geq 160 \mathrm{mmHg}$ dan diastolik $\geq 100 \mathrm{mmHg}^{10}$.

Tabel 1. Distribusi jenis preeklampsia di

Rumah Sakit Bhayangkara Palangka Raya tahun 2016

Jenis Jumlah

Persentase (\%)

\section{Usia Kehamilan}

Hasil penelitian menunjukkan bahwa kasus Preeklampsia diderita oleh ibu hamil paling banyak terjadi pada usia kehamilan 28-41 minggu/pada trimester ke-3 sebanyak 3 kasus. Hal ini dikarenakan hipertensi pada kehamilan lazimnya akan muncul pada $>20$ minggu usia kehamilan. Pada usia kehamilan trimester ke-3 merupakan fase fetal dimana maturasi dan pertumbuhan janin terjadi, efek dari senyawa asing pada trimester ketiga tidak berupa malformasi tetapi gangguan pertumbuhan ${ }^{9}$.

Ringan-Sedang $^{\mathrm{a}}$
Berat/Akut $^{\mathrm{b}}$
Total

\section{B. Karakteristik Obat}

Pada penelitian ini didapatkan data obat yang digunakan oleh pasien preeclampsia pada ibu hamil di Instalasi Rawat Inap Rumah Sakit Bhayangkara Palangka Raya tahun 2016. Data yang diperoleh dikelompokkan sesuai dengan kelas terapinya.

Pada tabel 2, dapat dilihat penggunaan obat untuk pasien 
preeklampsia pada ibu hamil terdiri dari antihipertensi yang diberikan adalah nifedipin dan metildopa yang merupakan terapi untuk preeklampsia ${ }^{10}$. Selain antihipertensi diberikan, pasien juga mendapatkan terapi cairan infus ringer laktat yang berfungsi supaya ibu hamil selalu terhidrasi, dan dalam proses melahirkan ringer laktat dapat mengurangi periode kontraksi dan relaksasi otot uterus $^{11}$.

Tabel 2. Distribusi obat-obat yang digunakan pada pasien preeklampsia di Rumah Sakit Bhayangkara Palangka Raya tahun 2016

\begin{tabular}{|c|c|c|c|}
\hline Kelas Terapi & $\begin{array}{c}\text { Nama } \\
\text { Generik }\end{array}$ & Jumlah & $\begin{array}{c}(\%) \\
\mathrm{N}=5\end{array}$ \\
\hline \multirow[t]{2}{*}{ Anti Hipertensi } & Nifedipin & 3 & $60 \%$ \\
\hline & Metildopa & 4 & $80 \%$ \\
\hline $\begin{array}{l}\text { Elektrolit dan } \\
\text { Mineral }\end{array}$ & Infus $\mathrm{RL}$ & 5 & $100 \%$ \\
\hline $\begin{array}{l}\text { Analgetik- } \\
\text { Antipiretik }\end{array}$ & Parasetamol & 1 & $20 \%$ \\
\hline Anti Konvulsan & $\mathrm{MgSO}_{4}$ & 3 & $60 \%$ \\
\hline Antiemetic & Ondansetron & 1 & $20 \%$ \\
\hline $\begin{array}{l}\text { Gangguan } \\
\text { Lambung }\end{array}$ & Ranitidin & 1 & $20 \%$ \\
\hline
\end{tabular}

\section{Golongan Obat Antihipertensi}

Golongan obat antihipertensi yang diberikan pada pasien preeclampsia pada ibu hamil di Instalansi Rawat Inap Rumah Sakit Bhayangkara Palangka Raya tahun 2016 adalah Calcium Channel Blocker-
Dihydropyridine (nifedipin) dan $\alpha 2$ - Agonis Sentral (metildopa). Nifedipin merupakan terapi lini kedua dari hipertensi pada ibu hamil dan metildopa merupakan terapi utama dari hipertensi pada ibu hamil karena dinilai paling aman dan tidak menimbulkan efek samping pada ibu dan janin.

\section{Kombinasi Obat Preeklampsia}

Obat Anti hipertensi yang dikombinasikan yaitu nifedipin dengan metildopa sebanyak 5 pasien (100\%). Penggunaan terapi kombinasi untuk pasien hipertensi pada ibu hamil dilakukan apabila monoterapi sudah dilaksanakan, tetapi tidak menunjukan perbaikan tekanan darah sehingga digunakan terapi kombinasi, dan juga dapat dilihat dari tingkat keparahan pasien ${ }^{12}$.

3. Evaluasi Ketepatan Penggunaan Antihipertensi

Ketepatan indikasi merupakan kesesuaian pemberian obat yang dilihat dari diagnosis dokter yaitu preeklampsia ringan-sedang dan preeclampsia berat pada ibu hamil.

Tabel 3. Aspek ketepatan Indikasi dan ketepatan obat Penggunaan Antihipertensi pada Pasien

\begin{tabular}{|c|c|c|c|c|c|}
\hline $\begin{array}{c}\text { Tekanan } \\
\text { Darah } \\
(\mathrm{mmHg})\end{array}$ & $\begin{array}{l}\text { Jumlah } \\
\text { Kasus }\end{array}$ & $\begin{array}{l}\text { Obat yang } \\
\text { diberikan }\end{array}$ & Alasan & Aspek & $\begin{array}{c}\text { Persentase } \\
(\%)\end{array}$ \\
\hline$<160 / 100$ & $2(40 \%)$ & Metildopa & $\begin{array}{l}\text { Antihipertensi } \\
\text { diberikan pada } \\
\text { pasien preeklamsia } \\
\text { ringan/sedang }\end{array}$ & $\begin{array}{c}\text { Tepat } \\
\text { Indikasi }\end{array}$ & \\
\hline$\geq 160 / 100$ & $3(60 \%)$ & $\begin{array}{c}\text { MgSO4 + } \\
\text { Nifedipin + } \\
\text { Metildopa }\end{array}$ & $\begin{array}{l}\text { Antihipertensi } \\
\text { diberikan pada } \\
\text { pasien preeklamsia } \\
\text { ringan/sedang }\end{array}$ & $\begin{array}{c}\text { Tepat } \\
\text { Indikasi }\end{array}$ & $100 \%$ \\
\hline
\end{tabular}


Tabel 4. Aspek ketepatan Obat Penggunaan Antihipertensi pada Pasien Preeklampsia di Rumah Sakit Bhayangkara Palangka Raya tahun 2016.

\begin{tabular}{lcccc}
\hline \multicolumn{1}{c}{ Nama Obat } & $\begin{array}{c}\text { Jumlah } \\
\text { Kasus }\end{array}$ & \multicolumn{1}{c}{ Alasan } & Aspek & Persentase (\%) \\
\hline Metildopa & $2(40 \%)$ & $\begin{array}{l}\text { Pasien mengalami } \\
\text { preeklamsia } \\
\text { ringan/sedang } \\
\text { Pasien mengalami } \\
\text { preeklamsia berat }\end{array}$ & Tepat Obat & $\mathbf{1 0 0 \%}$ \\
$\begin{array}{l}\text { MgSO4 + Nifedipin }+ \\
\text { Metildopa }\end{array}$ & $3(60 \%)$ & Tepat Obat & \\
\hline
\end{tabular}

Dari hasil analisis data diketahui bahwa penggunaan obat antihipertensi sudah tepat indikasi dan tepat obat, baik pada pasien preklamsia ringan/sedang maupun pasien preklamsia berat. Penggunaan obat pada saat kehamilan harus memperhatikan rasio manfaat dan resiko. Obat dapat digunakan jika manfaat diperoleh dengan penggunaan obat tersebut jauh lebih besar dari resiko yang ditimbulkan ${ }^{10}$.

Ketepatan obat dilihat dari pemilihan antihipertensi yang disesuaikan dengan standar yang digunakan, dilihat apakah merupakan drug of choice dari antihipertensi yang diberikan pada pasien preeklamsia. Pada penelitian ini $40 \%$ kasus preklamsia ringan sedang diberikan metildopa. Metildopa merupakan terapi lini pertama pada pasien preeklamsia karena dinilai paling aman dan tidak menimbulkan efek samping pada ibu dan janin ${ }^{10}$. Pada pasien preeklamsia ringan/sedang metildopa adalah antihipertensi yang paling sering direkomendasikan. Mengantuk merupakan efek samping yang ditimbulkan akibat penggunaan metildopa namun tidak menjadi masalah bagi pasien yang dirawat di rumah sakit ${ }^{13}$.

Tabel 5. Aspek Ketepatan Dosis Penggunaan Antihipertensi pada Pasien Preeklampsia di Rumah Sakit Bhayangkara Palangka Raya tahun 2016

\begin{tabular}{|c|c|c|c|c|c|}
\hline \multirow{2}{*}{ Kasus } & \multirow{2}{*}{ Nama Obat } & \multirow{2}{*}{$\begin{array}{l}\text { Dosis dan } \\
\text { frekuensi } \\
\text { pemberian }\end{array}$} & \multicolumn{2}{|c|}{ Literatur } & \multirow{2}{*}{ Keterangan } \\
\hline & & & Dosis & Buku/Guidline & \\
\hline $\begin{array}{c}1 \text { (Preeklampsia } \\
\text { ringan/sedang) }\end{array}$ & Methyldopa & $3 \times 500 \mathrm{mg}$ & $\begin{array}{l}250-1000 \\
\text { mg/haridalam } 2 \\
\text { dosis terbagi }\end{array}$ & $\begin{array}{l}\text { Drug Information } \\
\text { Handbook } 17^{\text {th }} \\
\text { edition }\end{array}$ & Sesuai \\
\hline $\begin{array}{c}2 \text { (Preeklampsia } \\
\text { berat) }\end{array}$ & $\begin{array}{l}\text { Infus } \mathrm{RL} \text { drip } \\
\mathrm{MgSO}_{4} 40 \%\end{array}$ & $\begin{array}{c}3 \times 6 \underset{\mathrm{gram}}{\operatorname{gra}}(15 \\
\end{array}$ & $\begin{array}{l}4-5 \text { g infus, } \\
\text { selanjutnya } 1-2 \\
\text { g/jam kontinyu } \\
\text { infus, } \\
\text { maksimum } 40 \\
\text { g/24 iam }\end{array}$ & $\begin{array}{c}\text { Drug Information } \\
\text { Handbook } 17^{\text {th }} \\
\text { edition }\end{array}$ & \\
\hline & Methyldopa & $3 \times 500 \mathrm{mg}$ & $\begin{array}{l}\text { g/24 jam } \\
\text { maksimum dosis } \\
\text { yaitu } 120-180 \\
\text { mg perhari } \\
250-1000 \\
\text { mg/hari dalam } 2 \\
\text { dosis terbagi }\end{array}$ & $\begin{array}{l}\text { Drug Information } \\
\text { Handbook } 17^{\text {th }} \\
\text { edition } \\
\text { Drug Information } \\
\text { Handbook } 17^{\text {th }} \\
\text { edition }\end{array}$ & Sesuai \\
\hline $\begin{array}{c}3 \\
\text { (Preeklampsia }\end{array}$ & $\begin{array}{l}\text { Infus RL drip } \\
\mathrm{MgSO}_{4} 20 \%\end{array}$ & $\begin{array}{c}3 \times 6 \text { gram }(15 \\
\mathrm{cc})\end{array}$ & $\begin{array}{l}4-5 \mathrm{~g} \text { infus, } \\
\text { selanjutnya } 1-2\end{array}$ & $\begin{array}{c}\text { Drug Information } \\
\text { Handbook } 17^{\text {th }}\end{array}$ & Sesuai \\
\hline
\end{tabular}




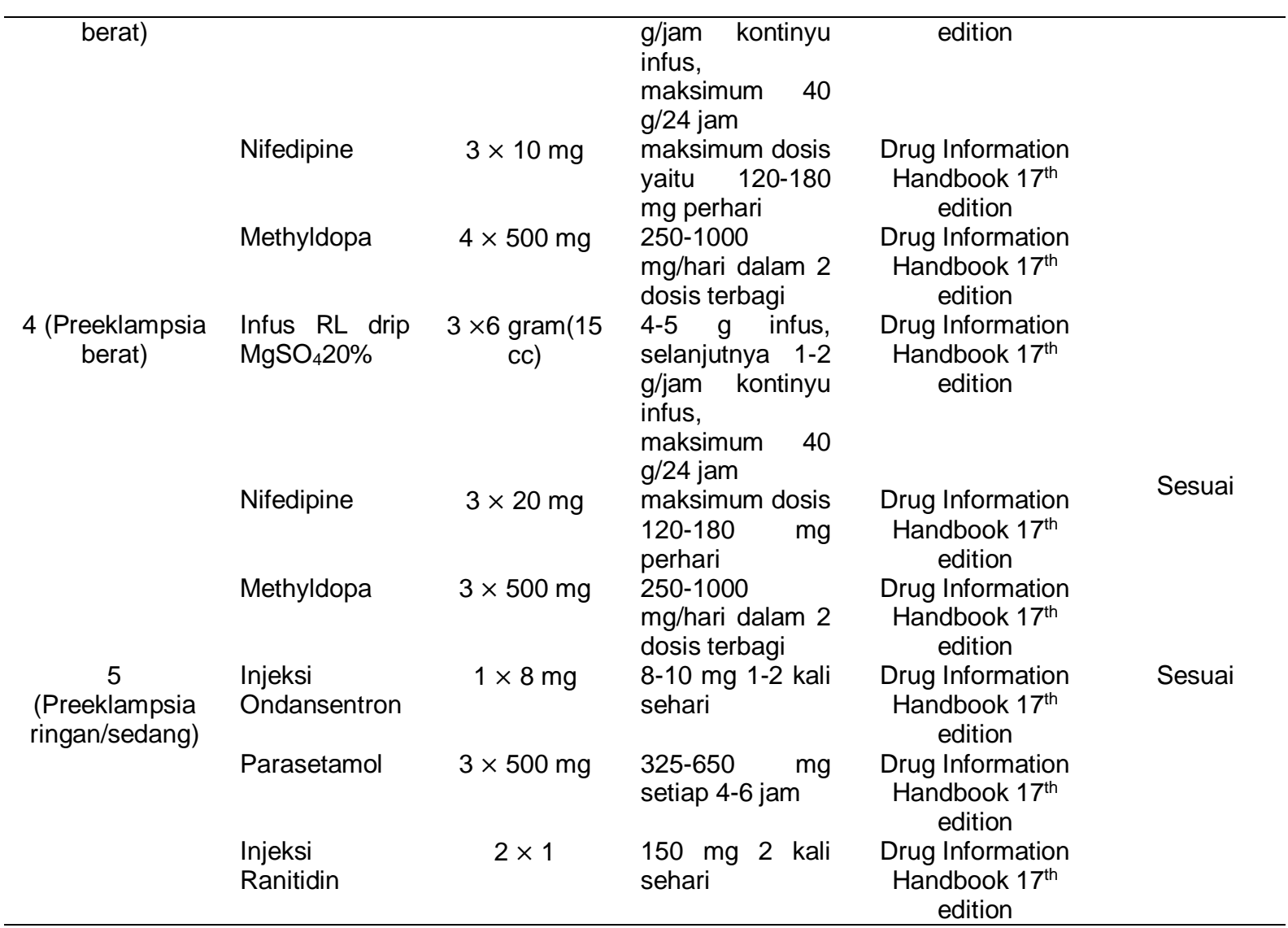

Pada kasus preeklamsia berat diberikan kombinasi obat antihipertensi nifedipin dan metildopa. Nifedipin sampai saat ini menjadi obat pilihan untuk hipertensi dalam kehamilan yang terdapat di Indonesia ${ }^{14}$. Nifedipin merupakan terapi linea kedua yang diberikan pada pasien preeklmasia $^{15}$, nifedipin berdasarkan FDA merupakan obat kategori $\mathrm{C}$ yaitu obat yang pada hasil studi terhadap binatang percobaan memperlihatkan adanya efek samping pada janin tetapi tidak ada studi kontrol pada wanita hamil sehingga obat hanya boleh digunakan jika besar manfaat yang diharapkan melebihi besarnya resiko terhadap janin.
Berdasarkan Royal College of Obstetricians and Gynaecologists[16], untuk penanganan preeklamsia berat metildopa dikombinasikan dengan labetalol karena beberapa studi menyatakan bahwa labetalol banyak memberikan keuntungan. Sehingga selain nifedipin, labetalol dapat menjadi terapi alternatif kombinasi dengan metildopa untuk kasus preklamsia berat. Magnesium sulfat yang diberikan pada kasus preeklamsia berat merupakan terapi pilihan untuk mengatasi kejang yang dialami pasien. 
Tabel 6. Aspek Ketepatan Pasien

Penggunaan Antihipertensi pada

Pasien Preeklampsia di Rumah

Sakit Bhayangkara Palangka Raya tahun 2016.

\begin{tabular}{|c|c|c|c|c|}
\hline $\begin{array}{c}\text { Nama } \\
\text { Obat }\end{array}$ & $\begin{array}{l}\text { Jumlah } \\
\text { Kasus }\end{array}$ & Alasan & Aspek & (\%) \\
\hline $\begin{array}{l}\text { Metildopa } \\
\text { MgSO4 + } \\
\text { Nifedipin } \\
+ \\
\text { Metildopa }\end{array}$ & $\begin{array}{l}2(40 \%) \\
3(60 \%)\end{array}$ & $\begin{array}{l}\text { Antihipertensi } \\
\text { yang } \\
\text { diberikan } \\
\text { kepada } \\
\text { pasien } \\
\text { termasuk } \\
\text { antikonvulsan } \\
\text { tidak } \\
\text { termasuk } \\
\text { kategori D } \\
\text { dan X } \\
\text { sehingga } \\
\text { aman untuk } \\
\text { ibu hamil }\end{array}$ & $\begin{array}{l}\text { Tepat } \\
\text { pasien }\end{array}$ & $100 \%$ \\
\hline
\end{tabular}

Tepat dosis adalah jumlah obat yang diberikan berada dalam range terapi. Pada penelitian semua obat sesuai dengan range terapi. Untuk evaluasi tepat dosis menggunakan Drug Information Handbook $17^{\text {th }}$ edition. Tepat pasien yaitu tepat pada kondisi pasien masing-masing, dalam artian tidak ada konraindikasi dan kemungkinan terjadi reaksi yang merugikan. Ketepatan pasien pada penelitian ini dilihat dari pemilihan antihipertensi yang disesuaikan dengan kondisi fisiologis dan patologis pasien, yakni ibu hamil dan dilhat ada tidaknya kontraindikasi obat terhadap ibu hamil. Pada penelitian didapatkan obat hipertensi yang diberikan pada pasien preeklampsia pada ibu hamil di instalasi rawat inap Rumah Sakit Bhayangkara Kota Palangka Raya 2016 menunjukan 100\% tepat pasien.

\section{KESIMPULAN}

1. Jenis obat yang digunakan pada pasien preeklamsia di instalasi rawat inap Rumah Sakit Bhayangkara Kota Palangka Raya tahun 2016 adalah metildopa sebanyak $80 \%$, nifedipin $60 \%$ dan $\mathrm{MgSO}_{4} 60 \%$

2. Pada Evaluasi penggunaan obat di instalasi rawat inap Rumah Sakit Bhayangkara Kota Palangka Raya tahun 2016 tidak ditemui adanya ketidaktepatan indikasi, obat, dosis dan pasien.

\section{DAFTAR PUSTAKA}

1. Sri, Novi. Analisis Faktor-Faktor Yang Berisiko Terhadap Preeklamsia Pada Ibu Bersalin Di Rsud Raden Mattaher Jambi Tahun 2016. 2016.Scientia Journal Vol. 5 No. 02 Desember 2016.

2. Nursal, D. G. A., Pratiwi T., Fitrayeni. Faktor Risiko Kejadian Preeklampsia Pada Ibu Hamil Di Rsup Dr. M. Djamil Padang Tahun 2014. 2015.Jurnal Kesehatan Masyarakat Andalas.Fakultas Kesehatan Masyarakat: Universitas Andalas. Padang: Sumatra Barat.

3. Djannah, N., S., dan Ika, S., A. 2010. Gambaran Epidemiologi Kejadian Preeklampsia/Eklampsia Di RSU PKU Muhammadiyah Yogyakarta Tahun 2007-2009. Bulletin of Health System Research Vol. 13 No. 4 Oktober 2010

4. Kementerian Kesehatan Republik Indonesia. 2015. Profil kesehatan Indonesia

5. Amri, M.U. 2015. Studi Penggunaan Obat Antohipertensi pada Pasien Preeklamsia Berat di Instalasi rawat Inap Rumah Sakit x Surakarta tahun 2014. Skripsi. Surakarta: Universitas Muhammadiyah Surakarta

6. Sidani, M. dan Siddik-Sayyid, S.M. 2011. Preeclampsia, A New Perspective in 2011. The Middle East Journal of Anesthesiology21(2), 207 216. 
7. Depkes RI.2009. Profil Kesehatan Indonesia 2008. Jakarta: Departemen Kesehatan Republik Indonesia

8. Agustin, Mega Lolytasari. 2015. Umur, Paritas, Kehamilan Ganda Dan Riwayat Penyakit Ibu Hamil Trimester III Yang Melatarbelakangi Kejadian Preeklampsia Di Rumah Sakit Umum Bangil. Laporan Penelitian. Mojokerto: Poltekkes Majapahit

9. Rozikhan. 2007. Faktor-faktor Risiko Terjadinya Preeklampsia Berat di Rumah Sakit. H. Soewondo Kendal. Cermin Dunia Kedokteran edisi 158

10. JNC VII. 2003. The seventh report of the Joint National Committee on prevention, detection, evaluation, and treatment of high blood pressure

11. Dawod, F., Dowswell, T., Quenby, S. 2013. Intervenous Fluids for Reducing the Duration of Labour in Low Risk Nulliparous Women. The Cochcrane Collaboration

12. Amri, Muhammad Ulil. 2015. Studi Penggunaan Obat Antihipertensi pada Pasien Preeklampsia Berat di Instalasi Rawat Inap Rumah Sakit X Surakarta Tahun 2014. Surakarta: Fakultas Farmasi Universitas Muhammadiyah Surakarta.

13. Duley, L., Shireen M., and Edgardo A. 2006. Clinical Review Mangement of Pre-Eclampsia. BMJ. Vol 332 February

14. Perkumpulan Obstetri dan Ginekologi Indonesia (POGI).2006. Standar Pelayanan Medik Obstetri dan Ginekologi. Mitra Bestari Jakarta

15. Brown, Catherine $M$ and Garovic Vesna D. 2014. Drug Treatment of Hypertension in Pregnancy. Drugs. 74: 283-296

16. Royal College of Obstetricians and Gynaecologists.2010.The Management of Severe Pre-Eclampsia/Eclampsia. RCOG Guidline No. 10 (A) 